\title{
Information: a strategic resource for technological change
}

\author{
Jean-Marie Leclerc \\ Directeur général, Centre des Technologies de l'Information (CTI), Genève, Switzerland; \\ Tel. : +4122327 79 67; Fax : + 41223274877
}

jean-marie.leclerc@etat.ge.ch

Abstract: Our society, formerly industrial, is nowadays changing into an 'e-society', built on technology, information, communication and knowledge. This transition is facilitated by the tremendous developments in the Technology of Information and Communication (TIC). In this 'e-society' a new model of organisation is developing: the classical hierarchy is changed into a network designed organisation. From an economic viewpoint companies and the state are aiming at the maximisation of their profits, privileging cost-effective activities and reducing their cost. From a social viewpoint the present social system is more based on economical subsistence than focused on the essential needs of individuals. This results in serious social troubles, such as protestation, inequalities, and potentially aggressive frustrations. Exclusion is increasing in micro-societies as well as in cultures. The spread of new technologies produces a gap between those who can contribute and those who are left behind, creating the risk of cyber-exclusion. Only a sustainable development approach in governance will be able to balance the real needs of the citizens with respect to social, economic and environmental issues.

Key words: communication, cyber-exclusion, e-Society, information, knowledge, network organisation, sustainable development, technology 


\section{GOVERNANCE FOR HUMAN SUSTAINABLE DEVELOPMENT}

In order to reach a more human 'e-society', in spite of its mechanical nature, one must notice the importance of societal indicators on the charts of governance institutions. According to the United Nation Development Program (PNUD) not only states are involved, but private sector and civil society as well. Social change funds, as well as technological expertise, are essential elements. However, postulating a planetary technological revolution implies implementation of Information and Communication Technology (ICT) at each level of the population and in every location, compatible with every political system. Nevertheless, it is only through individuals that technology can be socially implemented and integrated, thus gaining credibility.

Society consists of institutions, relations and norms which determine the quality and the quantity of social interactions. Social capital dynamically offers a common space for groups and communities, contributing to interresolution of problems. Social capital is not only the total of societal institutions, but also the cement which knits them together, influencing the intensity and the quality of social cohesion.

Social cohesion not only results in social values, but also significantly contributes the economy. It is an essential factor in enhancing sustainability as well as long term development. Moreover social cohesion is a guarantee for good circulation of information, communication and knowledge. These are the keys for success and autonomy in the new networked situation. In order to successfully switch to an 'e-society' based on sustainable human development governance, it is necessary to create network organisations using strategies focused on individuals.

To social and human capital organisations must, in the first place, apply principles of management based on solidarity, complementarity and balance. In the second place they should heighten civil society awareness about the role of ICT.

\section{INFORMATION TECHNOLOGIES AND OPEN COMMUNICATION}

'E-society' is not only focused on individuals, it also depends on the coordination of States, private sector and civil society, especially with respect to ICT performance. Information systems must be accessible, and therefore open. Moreover they should also smoothly fit organisational 
processes and guarantee satisfaction of identified needs, sustainability and confidentiality. UNESCO, the United Nations Educational, Scientific and Cultural Organisation, recommends development of Open Source software in order to enhance solidarity, cooperation and collective work among developers and users of new technologies. When built on Open Source software, information systems favourably contribute to the transition toward an open 'e-society' through wide networked accessibility, thus producing social capital.

Technology indeed has two faces: a rather exciting one, as well as a threatening one. On the one hand technologies extend the human potential with respect to calculation, simulation, communication, etc. But on the other hand the outcomes of their use are quite uncontrollable. To be realistic, not driven by an illusion of omnipotence, nor hindered by existing boundaries, this ambivalence must be part of a comprehensive approach of information management. This implies that it is the current mission of States, private sector and civil society to integrate differences in pace, funds and priorities. On the one hand 'Cyber-inclusion' is the only way forward, while on the other hand critical observation must lead to efficient risk management.

\section{'CYBER-INCLUSION'}

The definition of exclusion is logically connected to that of inclusion. Indeed, criteria of inclusion define de facto reasons for exclusion. But this is not sufficient to explain the issue. Powerful majorities, by lobby or by consensus, also play a role. Also, next to economical and social criteria, moral and ethical criteria also enlarge the number of constraints in the system. Through its integrating power every society logically also produces exclusion. Unfortunately these exclusions are reproduced by education, history, believes and moral code. Modern society does not escape this perverse cycle: barbarous exclusions are to be encountered on account of race, health abilities, sexual orientation, nationalism, employment, etc. If no action is taken, our modern life, based on technologies and information science, will produce firstly numeric and secondly economical exclusion.

The current challenge is not to eradicate exclusion and injustices all at once, but rather to benefit from world wide communication and networks to bring specific patterns to light. For 'e-society', as a sub-ensemble of common society, the same rule applies: injustice will go on. The main concern should be: how to intervene so that 'e-society' will not add a new type of exclusion, but will rather allow a new type of inclusion for those previously excluded by the criteria of other sub-ensembles. 'Cyberinclusion' can be promoted in three domains: 
1. 'Cyber-inclusion' by technology: sufficient technological devices (computers, software, Internet networks, etc.), as well as legal structures guarantee access to 'e-society' for individuals and more general players.

2. 'Cyber-inclusion' by knowledge: as part of a dynamic and comprehensive learning process, ICT is accessible to everybody at different times in life.

3. 'Cyber-inclusion' by activity: a "three dimensional information approach" with three types of activities:

a) Necessary activities: activities which are needed by social and economic spheres in order to be reliable;

b) Requested activities: outcome of demands expressed by potential clients, ready to give a mandate;

c) Feasible activities: human capital able to respond to requested activities as an efficient means to realise entrusted mandates.

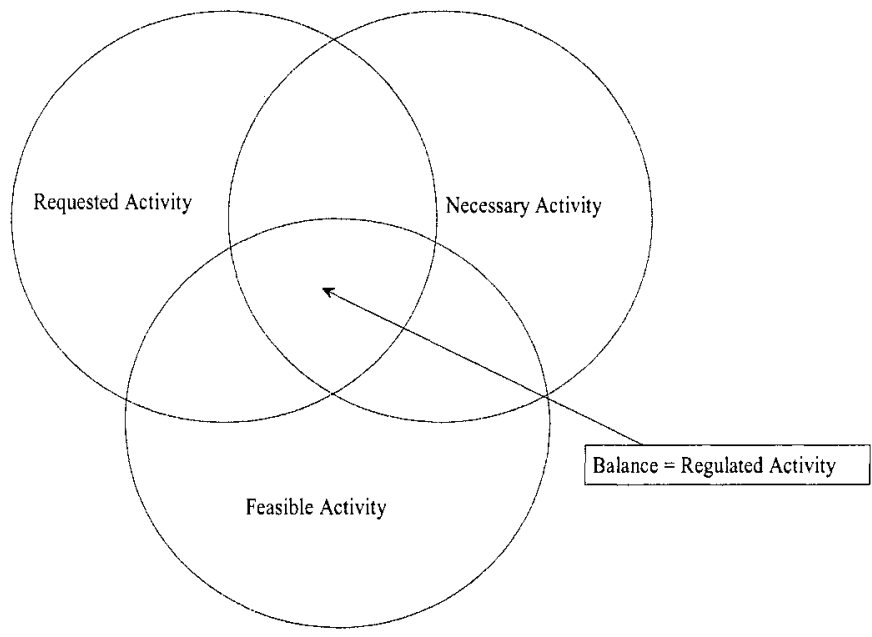

Figure 1. Activities in the three-dimensional information approach

The intersection of the three circles in Figure 1. is the zone of best balance between the various activities, containing 'regulated activities'.

Today, feasible activities are in general those that produce maximum profit. However, the volume of requested and feasible activities is constantly decreasing. An immoderate level of maximisation of profit can only be attained by a small number of people who have the level of requested 
competences for its realisation. This increases the number of excluded, while a few get tremendous profits.

However, $70 \%$ of current activities are not yet transformed into requested and feasible activities, because these do not allow maximization of profits. These activities offer the possibility to contribute to social security by integrating into the economical circuit people who were previously excluded. Financial autonomy, as well as added value to society, is the valuable result of this new type of contribution.

\section{TECHNOLOGICAL CYBER-INCLUSION}

The integrating power of ICT becomes very clear in the light of overcoming handicaps. Not only does the technology extend our capabilities in communication, calculation, programming and simulation, but equally execution of tasks and interconnected teamwork are in the reach of all, through simple adaptations on the logistic level. A Braille line connected to the computer is an example of how simple inclusion can be extended to the blind population.

Open Source software contributes significantly to building networks that function in human sustainable governance mode. Concretely speaking, technological 'cyber-inclusion' is providing services to civil society, such as access, knowledge and activities which here are considered as the three main elements.

\section{CYBER-INCLUSION THROUGH KNOWLEDGE}

According to the Organisation for Economic Co-operation and Development (OECD) human capital can be defined as: "knowledge, qualifications, skills and other qualities possessed by an individual". Therefore, the more individuals enlarge their human capital, the broader and the richer 'e-society' will be. Contrary to a tendency among some players in our society to keep back information and keep competence low 'e-society's dynamics' totally turns this around. The first universal skills are information and human capital management skills. Flexibility in dealing with information and abstractions is one of the fundamental competences for participating in the 'e-society's activities'. Such qualification should be developed in the economic and/or civil society sphere. 


\section{CYBER-INCLUSION THROUGH ACTIVITY}

Every individual has the right of personal expression in activities for developing one's potential. On the other hand everyone should contribute to the generalisation and recognition of this particular right. The challenge of cyber-inclusion is technological development and inclusion of minorities, such as handicapped people and marginalised lifestyles, in parallel. Least developed countries must also be integrated into this planet wide change. This can mainly be done by searching the appropriate environment for the target population, based on their established potentials, and then to foster emergence of networks.

Three fundamentals principles are assisting in this process: integration as foremost concern, the three-dimensional approach of activity harmonising the implementation and thirdly, translation into action through adequate structures, promoting cyber-inclusion as well as flexibility of networks.

\section{THE E-SOCIETY REPOSITORY}

As mentioned before the current mission of states, private sector and civil society is to realise the integrating and developing process, dealing with differences in pace, funds and priorities. Additionally, critical observation has to be included to manage the various risks. Information society has a significant strategic dimension. To coordinate, diffuse and value information are actions which are necessary to regulate and to back up any technological change. An e-society repository can help in successful implementation as a tool, not only to build and follow projects, but also as road map including forgotten aspects such as ethics and coordination.

Two illusions threaten success. The first is the wish for absolute control. As we are speaking of a planet wide change, the manifestation of this illusion can take unlimited form and expression. On the other hand local adaptation and individual assertion are normal phenomena. The pay back is an extended market, based on generated activity. Rather than taking advantage of monopolisation of technology, information technology that is everywhere equally implemented, will create much broader markets and much more prosperous opportunities. This is in line with the insatiable request for multi-lateral exchange, expressed internationally as well as nationally. The second illusion concerns transparency in terms of strategy. In the common race to success and profit the most up to date strategy is an absolute necessity. However, surprisingly only a common vision can guarantee individual existence. Globally thought, locally implemented and 
individually expressed, that is the key to combine natural development and electronic contribution.

In this the notion of e-repository becomes a common message, subsequently translated into local action. It acts as a technological observatory, a solution reservoir, where analysis, expertise, knowledge and competence can be regrouped, shared and capitalised. In this way the strategic component of information stays open and accessible. In the end open communication and ethics reduce the threat of uncontrolled creation, which technology sometimes brings about. Thus human sense is preserved without market and environment constraints.

\section{HUMAN BEING AS MAIN CONCERN}

Social cohesion as well as social capital can be the result of this cyberinclusion approach, but only if network organisations are developed and empowered. These seem to provide the best environment for developing human capital through activities and through exchange of knowledge and skills.

Networks, as boosters of human capital, are the answer to problems with subdivided and centralised power. The classical pyramidal (hierarchic) organisation slows down initiative and reduces autonomy. On the other hand a network organisation fosters transversal relationships and especially vertical and transversal circulation of information. Withheld information is therefore a loss of potential. The e-approach prevents subsidiary circulation of information, which often separates the monitoring process from the activity process. The raw material of 'e-society' can therefore be defined as knowledge and skills. Thus, a human network structure delimits the framework of action for "e-activities". Inside this framework, autonomy is highly recommended and social cohesion, through interdependency, is preserved by interconnection and exchange of information.

Human concerns also integrate economical constraints, as trade is a major key to sustainable development. Therefore the extension of human capital, through networks and cyber-inclusion, should not be perceived as a "charitable attitude", but rather as the only rational cold approach to remain competitive in e-business and e-trade. 


\section{CONCLUSION}

The current challenge is to create a new vision of technological potential and value, taking into account changes requested by civil society. Respecting economical constraints, human development can therefore "surf" on the natural tendency of technological advancement. The evolution of ICT brings world wide communication within reach and creates consequently not only a comprehensive awareness, but also insight into proximity through connexion.

Parallel to these innovations, society is being artificially divided into those who have this particular access and those who are deprived of it. Two regulations are possible by the environment: either "natural selection" or coordination of the various players. States, private sector as well as civil society must be actively involved, so that creation of markets and new activities can be promoted and developed. This is more a strategy of autonomy arranged by states, civil society and private sector, rather than competitiveness orchestrated by profits.

The professional sphere is switching to network organisation in order to break the hierarchic shell. The use of technology in society shows that machines are easily integrated and assimilated: technology is thus not a danger for social balance, but rather a tool for development. Therefore, to remain sustainable, markets must aim at adaptation and flexibility focused on individuals and take into account human variables. Rather than retain progress and monopolise information management, technology must work for cross-cultural and world wide communication, potentially spread out to everyone.

In conclusion, the profound change from industrial times to he information era must be supported: socially - through cyber-inclusion, economically - through creation of new markets, and with equity - through multi-lateral development projects. Consequently new technologies will not be a threat of social disturbance, but rather a tool for autonomy and flexibility of individuals.

\section{BIOGRAPHY}

Jean-Marie Leclerc is director of the Centre of Information Technologies (CTI) in the State of Geneva (Etat de Genève) since March 2001. He gained his $\mathrm{PhD}$ at the University of Compiègne, Paris, France and his thesis was dedicated to the conception of information's systems in decentralized and multi-disciplinary environments. He has international contact, particularly in the field of development of information science related to health systems. He 
is lecturer at the University of Neuchâtel and several Swiss schools for engineers in telecommunication and management. $\mathrm{He}$ is active in the development of multilateral exchanges among public administrations, especially in the region of Neuchâtel (inter-administration project), Switzerland. 